\title{
Cara Kerja Ilmu Sosial Agar Sehandal Dan Sehebat Ilmu Alam
}

\author{
Muhammad Faqih, M.Pd \\ (muhammadfaqih444@gmail.com)
}

\begin{abstract}
Abstrak
Kehebatan dan kehandalan ilmu alam dalam memecahkan masalah alam terbukti handal dan terus berkembang. Hal ini tidak terjadi pada ilmu sosial. Banyak persoalan sosial yang tidak dapat dipecahkan oleh ilmu sosial. Para ilmuwan tergoda menggunakan model kerja ilmu alam seperti Auguste Comte yang menjadikan Sosiologi sebagai fisika sosial. Husni Muadz (2016) membuat model sosial ideal dengan cara berpikir deduktif melalui pendekatan filosofis - teoritis. Tujuan dari kajian ini adalah untuk membangun model sosial ideal dengan pendekatan agama melalui cara berpikir induktif. Hasil penelitian menemukan hukum yang berlaku pada dunia sosial dan cara kerja ilmu sosial di masa depan agar sehandal ilmu alam.
\end{abstract}

Kata kunci: cara kerja, ilmu sosal, ilmu alam

\section{PENDAHULULUAN}

Ilmu Alam menjadi handal dan berkelanjutan karena peran besar dari Sir Isaac Newton pada awal masa pencerahan. Peran terbesarnya ketika Newton menemukan hukum Newton 1, II, dan III. Hukum yang paling terkenal adalah hukum tentang gerak dan gaya benda-benda di alam semesta. Hukum ini terkenal dengan nama hukum gravitasi. Berdasarkan hukum gravitasi, semua ilmuwan baru mengerti mengapa semua benda mengitari Matahari dan Bumi berputar pada porosnya.

Berdasarkan hukum gravitasi maka para ilmuwan dapat menjelaskan gaya tarik dan gerak benda-benda langit termasuk Bumi melalui suatu mekanisme yang tetap yaitu model gravitasi. Selanjutnya model gravitasi ini menjadi model dalam menjelaskan pergerakan dan gaya tarik benda-benda langit. Hukum Newton sampai sekarang tetap dipelajari dan berkembang hingga Albert Einstein menemukan model baru. Model gravitasi menjelaskan mengenai pergerakan dan gaya tarik benda langit yang dengannya dapat dijelaskan semua pergerakan dan gaya tarik benda di alam semesta. Jika terjadi pergerakan dan gaya tarik yang deviasi atau menyimpang dari model itulah yang perlu mendapat penjelasan dalam bentuk hukum atau hipotesis.

Berdasarkan pengalaman Newton menemukan teori gravitasi, Toulmin (dalam Husni Muadz, 2016: 34) menyebutkan empat langkah ilmuwan alam dalam membangun teori yaitu: 1) Membuat model ideal dari alam semesta terlebih dahulu; 2) Kemudian melihat realitas alam saat ini, mana yang mengalami penyimpangan dari model ideal yang telah dibuat; 3) menyusun teori, hukum, dan hipotesis untuk menjelaskan secara teoritis mengapa terjadi penyimpangan; 4) menerapkan teori ke dalam ilmu alam. Ilmu sosial tidak memiliki keempat langkah tersebut dalam membangun teori. Hal inilah yang menyebabkan ilmu sosial belum menjadi ilmu yang handal dan berkelajutan.

Ilmu sosial selama ini dalam membangun teori dimulai kasus-kasus tertentu dan langsung mengambil data, menganalisis dan menyusun hipotesis hasilnya diterapkan dalam ilmu sosial. Kalangan ilmuwan sosial beralasan tidak mengikuti langkah ilmu alam dalam membangun teori karena data sosial yang bersifat heterogen, tidak seperti ilmu alam yang datanya bersifat homogen. Namun Auguste Comte berusaha keras menjadikan sosiologi sebagai fisika sosial, yang mengikuti hukum-hukum tetap sebagaimana hukum alam. Namun tentu saja hukum alam tidak sama dengan hukum sosial. Masalah ini belum terpecahkan oleh ilmu sosial sampai sekarang.

Muadz (2016) mencoba memecahkan persoalan tersebut dengan mengikuti langkahlangkah yang ditawarkan Tolumin (1974) dengan membuat model sosial yang ideal terlebih dahulu. Untuk kepentingan tersebut Muadz menggunakan pendekatan Nalar 
sistem. Muadz (2016) pertama-tama melakukan pembedahan anatomis terhadap sistem sosial. Pembedahan menggunakan analisis filosofis dan teoritis secara bersamaan. Muadz menyebutnya sebagai rekonstruksi Sistem sosial dengan menggunakan nalar sistem. Menurut penulis, Muadz (2016) menempuh cara berpikir deduktif dalam membuat model sosial ideal. Cara berpikir yang dimulai dari konsep umum dan dari konsep umum ditarik kesimpulan untuk memecahkan masalah-masalah yang khusus.

Artikel ini mencoba memecahkan hal yang sama akan tetapi menggunakan cara berpikir yang berbeda dan dengan pendekatan yang berbeda. Penulis menggunakan cara berpikir induktif dengan pendekatan nalar agama. Pertanyaan penting dalam tulisan ini adalah bagaimana membangun model sosial ideal dengan pendekatan nalar agama melalui cara berpikir induktif. Maka tujuan dari kajian ini adalah untuk membangun model sosial ideal dengan pendekatan agama melalui cara berpikir induktif.

\section{Metode Kajian}

Tulisan ini menggunakan pendekatan kualitatif deskriptif. Pendekatan ini lebih menekankan makna dan bukan pengukuran data. Metode kajian yang tepat adalah studi literatur (kepustakaan). Sumber data utama bersumber dari teks, buku, artikel, dan data pustaka seperti jurnal, informasi dari internet. Sumber data dibedakan menjadi dua; 1) sumber primer; data ini berasal dari Alquran dan hadist.; 2) sumber sekunder. Data berasal tulisan orang lain mengenai pendidikan karakter.

Teknik analisis data menggunakan teknik analisa data kualitatif dengan melakukan reduksi data sesuai dengan permasalahan saja. Tulisan yang tidak terkait dengan permasalahan tidak dijadikan sebagai acuan dan kategorisasi. Sedangkan tulisan yang relevan akan menjadi rujukan.

Setelah data terkumpul selanjutnya menganalisis data. Analisis data dengan menggunakan teknik analisis isi (conten analysis). Analisis ini merupakan teknik yang menganalisis data secara sistematis untuk menyederhanakan data kedalam kata dan teks serta naskah agar menjadi lebih padat.
Prosedur analisis bersamaan dengan proses pengumpulan data dengan cara menuliskan, mengedit, mengklasifikasi, mereduksi, dan menyajikan data. Menurut Miles, Hubermann, \& Saldana (2014) meliputi pengumpulan data, reduksi data, kondensasi data, penyajian data, dan penarikan kesimpulan.

\section{Landasan Teori}

Kesadaran difahami sebagai suatu kondisi terjaga atau menyadari kondisi secara mental seperti mengamati, merasakan, dan berpikir. Ada tiga teori mengenai kesadaran pertama teori orde pertama yang berpandangan bahwa keadaan mental disadari saat seseorang menyadari sesuatu. Kedua teori ruang kerja global jika suatu negara sadar tersedia proses mental. Teori indera bathin suatu keadaan dimana seseoarang merasakan dan mempersepsikan sesuatu berdasarkan fakultas bathin (Rosenthal, D.M. 2009)

Sen (2008) mengartikan kesadaran sebagai esensi atman, diri primal, dan imanen yang diidentifikasikan sebagai Brahman. Suatu yang murni, transenden yang menjadi landasan menjadi manusia dan alam. Plato dan Descartes membagi alam menjadi dua yaitu materi dan subtansi (jiwa dan Roh). Kesadaran berhubungan dengan subtansi seperti jiwa dan roh. Perkembangan pemikiran barat yang materialistik menyebakan kesadaran difahami hanya sebagai fungsi otak dan pemerosesan informasi , misalnya seperti Spery (1969) yang mengartikan kesadaran sebagai dualis property kesadaran merupakan properti khusus yang bersifat non fisik tetapi muncul melalui sistem fisik seperti otak. Crick (1994) dan Dennet (1991) mengartikan kesadaran sebagai fungsi otak semata. Kesadaran tidak lebih dari sekedar pemerosesan informasi. Baars (1988) fungsi otak bekerja untuk mengingat, memperhatikan, eksekutif pusat dan ruang kerja global.

Tidak ada kesamaan persepsi mengenai definisi kesadaran. Sloman (1991) misalnya menganggap orang yang mengartikan kesadaran sesungguhnya sedang menipu dirinya sendiri. Stanovich (1991) juga dengan gemas menganggap "kesadaran sebagai konsep yang gagal". Velmans \& Goldsmith (2009) mendefinisikan kesadaran sebagai apa yang diamati dan alami. Jadi kesadaran 
berkaitan dengan ada atau tidaknya fenomena yang diamati dan alami. Konten fenomenal hadir ketika sadar dan jika konten fenomenal tidak hadir kesadaran juga tidak ada. Dengan demikian isi kesadaran adalah semua fenomena yang kita amati dan sadari.

Semua ornganisme menunjukkan perilaku belajar yang beragam bentuk hal ini menunjukkan bahwa semua organisme memiliki sesuatu yang disebut "kesadaran inti" (Damasio, 1999). Kesadaran adalah keadaan internal tentang benda eksternal (Brentano, 1982).

Berbagai teori yang ada dapat disebutkan antara lain:

1) Teori Kesadaran Mental Tingkat Tinggi. Yakni keadaan mental yang sadar, simultan, non inferensial yang isinya adalah kebenaran (Carruthers, P. 2000; Rosenthal, 1997).

2) Teori Refleksi menekankan hubungan antara kesadaran dan diri. Teori refleksi menempatkan diri dalam keadaan sadar itu sendiri. persepsi sadar mengarahkan objek eksternal menuju dirinya (Gennaro, 2012, Kriegel \& Willigord, 2006).

3) Teori Kesadaran Refresentasionalis berpandangan bahwa kesadaran dan keadaan refresentasi adalah satu dan sama (Tye, 1995).

4) Teori Kesadaran Narative Interpretatif bahwa kesadaran adalah hasil bukan dari fakta tetapiinterpretasi yang lebih besar (Dennet, 1991); Gazzaniga, 2011).

5) Teori Kesadaran Ruang Kerja Neuronal Global (GNWT) kesadaran sebagai persaingan antara prosesor dan keluaran untuk sumber daya yang terbatas untuk menyampaikan infoormasi yang disadari selama tersedia untuk ruang kerja global (Baars, 1988; Dehaene \& Naccache, 2001)

6) Teori Kesadaran Informasi Integral. Pada dasarnya kesadaran ditentukan oleh integrasi informasi terlepas direalisasikan pada kesadaran buatan maupun biologis (Koch, 2012)

7) Teori Syaraf berpandangan bahwa kesadaran ditentukan oleh urat syaraf (Metzinger 2000).
8) Teori Kesadaran Kuantum berpandangan bahwa tempat kesadaran berada diluar syaraf (Hameroff, \& Penrose, 2014).

9) Teori Kesadaran Non Psikis berpandangan bahwa kesadaran adalah realitas non fisik sesuatu yang tidak dapat direduksi menjadi realitas alam fisik (Charmer, 1996).

10) Teori Kesadaran Intrinsik berpandangan bahwa kesadaran melekat pada struktur otak dimana antara otak dan kesadaran terhubung melalui kebutuhan bersyarat yaitu selama otak hidup dan memenuhi kondisi minimal maka akan ada tingkat kesadaran (Farisco, M. 2019).

Penulis berpandangan bahwa kesadaran adalah dua fungsi dari operasi Subtansi (Jiwa dan Roh) dan Materi (fungsi otak). Subtansi kesadaran bekerja sebagai pengatur dan Otak bekerja sebagai yang diatur. Keduanya berfungsi secara integral bisa juga berfungsi secara sendiri-sendiri. hal ini menunjukkan bahwa kesadaran berhubungan dengan materi dan non materi. Dunia kesadaran hanya berlaku hukum kesadaran tidak bisa berlakuk hukum alam sebagaimana yang dilakukan Comte menjadikan sosiologi sebagai fisika sosial. Kesadaran tidak dapat dijadikan menjadi fisika kesadaran.

\section{Pembahasan}

Jika hendak mengikuti pola kerja ilmu alam dalam menemukan model ideal maka ilmu sosial pertama-tama membuat model ideal kehidupan di alam semseta ini terlebih dahulu. Model sosial ideal di alam semesta dapat ditemukan manakala mengikuti pengalaman Newton dalam menemukan model ideal alam semesta. Penulis menawarkan cara berpikir induktif. Model sosial ideal akan dapat ditemukan melalui kasus yang khusus lalu mengambil kesimpulan yang bersifat umum.

Penulis menjadikan pengalaman Newton menemukan model ideal alam sebagai kasus khusus kemudian menariknya ke dalam kasus sosial. Maka penulis menggunakan analisis persamaan agar hasilnya sama.

Pengalaman Newton menemukan model ideal alam bermula dari benda yang jatuh ke alam adalah Apel (sebuah benda), maka dalam ilmu sosial harus ada benda jatuh 
juga, tentu saja bukan benda tetapi sesuatu yang hidup salah satunya adalah orang (manusia). Jika dalam ilmu alam benda yang jatuh itu namanya Apel, maka dalam ilmu sosial orang yang jatuh itu juga harus ada namanya, siapa namanya? Jika dalam ilmu alam benda (apel) yang jatuh itu ke tanah, maka dalam ilmu sosial orang yang jatuh itu kemana? Kalau jatuhnya ke tanah maka tanah mesti diberi nama juga, apa namanya? Jika dalam ilmu alam Newton mengajukan pertanyaan kritis, maka dalam ilmu sosial juga mesti ada pertanyaan kritis. Apa pertanyaan kritisnya?

Sejauh ini ilmu sosial tidak memberikan jawaban, ilmu pendidikan, ilmu ekonomi, ilmu geografi, ilmu sejarah, dan sosiologi) juga tidak menyediakan jawaban kecuali ilmu agama. Ilmu agama menyediakan jawabannya. Menurut ilmu agama Islam satusatunya orang yang pernah mengalami jatuh dari tempat yang tinggi ke tanah adalah ADAM. Berdasarkan surah Albaqarah: 35-36). Sekarang ilmu sosial menemukan pola persamaannya dengan ilmu alam. Ada benda yang jatuh, ada orang yang jatuh (pola persamaan pertama) benda yang jatuh namanya Apel dalam ilmu alam dan orang yang jatuh naman Adam dalam ilmu sosial/Agama (pola persamaan kedua). Apel jatuh ke tanah dalam ilmu alam dan Adam jatuh ke bumi dalam ilmu sosial (pola persamaan ketiga). Mengapa Apel jatuh ke tanah? Pertanyaan kritisnya dalam ilmu alam, Mengapa Adam jatuh ke bumi? Pertanyaan kritisnya dalam ilmu sosial (pola persamaan keempat).

$$
\text { Lagi-lagi ilmu sosial tidak }
$$
menyediakan jawabannya, kecuali mengambil jawaban dari ilmu agama. Menurut ilmu agama penyebab jatuhnya Adam adalah karena telah mendekati pohon terlarang yang menyebabkan Adam berbuat ZHALIM (QS: $2: 35-36$ ) Adam mendekati pohon telarang karena mengikuti pola pikir Syaitan (Al A'raf: 20-24). Meskipun kita sudah menemukan jawabannya akan tetapi jawabannya tetapi mengapa Adam mengikuti pola pikir Syaitan. Alquran menjelaskannya hanya sebatas itu, selebihnya menjadi wilayah berpikir manusia. Wilayah inilah yang diambil oleh Newton sebagai hukum bahwa ada hukum yang mengatur semua benda yang jatuh ke tanah. Maka ilmu sosial harus membuat hukum yang berlaku pada kehidupa sosial yang mengatur semua orang yang jatuh ke bumi yaitu membuat hukum yang berlaku pada alam sosial (pola persamaan kelima).

Untuk kepentingan tersebut maka penulis juga mengajukan hukum yang mengatur orang yang jatuh ke bumi. Hukum ini di sebut Hukum Faqya I dan II. Hukum Faqya I disebut HUKUM KESADARAN UMUM berbunyi:

1) Semua makhluk hidup diatur dan dipelihara melalui suatu mekanisme tetap yang disebut Daya Hidup

2) Setiap makhluk hidup memiliki daya hidup yang terbatas, kecuali ada daya yang resultannya tak terbatas yang bekerja pada makhluk hidup itu.

3) Daya hidup bekerja melalui mekanisme yang sama yaitu kesadaran (Konsiustasi).

4) Setiap makluk hidup akan menggunakan kesadarannya atau tak menggunakan kesadarannya kecuali ada daya sadar lain yang bekerja untuk mengubahnya.

5) Daya sadar berfungsi untuk mencapai keseimbangan/keadilan.

Hukum Faqya II disebut HUKUM KESADARAN KHUSUS yang berbunyi:

1) Kesadaran bekerja melalui mekanisme Pengujian

2) Pengujian bekerja melalui mekanisme Perintah (Instruksi)

3) PERINTAH diterima jika BENAR

4) PERINTAH ditolak jika MELANGGAR

5) Kesalahan dapat diperbaiki melalui mekanisme perbaikan kesadaran (Rekonsiustasi)

\section{Operasi Kesadaran}

Untuk mengetahui hukum kesadaran itu berfungsi maka perlu dibuktikan dengan contoh kasus. Dibawah ini ada empat kasus untuk menguji hukum kesadaran:

1) Jika A memberikan daya sadar kepada $M$, untuk menjadikan A' sebagai A+ sebesar $\mathrm{F}$, maka M memberikan daya sadar sebesar - F. F dan - F memiliki besar yang tidak sama namun arahnya sama jika A' terbukti benar. (Operasi Sadar) 
2) Jika A memberikan daya sadar kepada $A^{\prime}$ sebesar F, maka A' memberikan daya sadar sebesar F. F dan F memiliki besar yang sama dan arahnya sama, dan A' terbukti benar. (Operasi Sadar)

3) Jika A memberikan daya sadar kepada J, untuk menjadikan A' sebagai A+ sebesar $\mathrm{F}$, maka $\mathbf{J}$ memberikan daya sadar sebesar $+\mathrm{F}$. F dan $+\mathrm{F}$ memiliki besar yang tidak sama dan arahnya terbalik setelah A' terbukti benar. (Operasi Taksadar)

4) Jika S memberikan daya sadar kepada $A^{\prime}$ untuk menjadi A- sebesar F. maka A' akan memberikan daya sadar sebesar F. F dan F memiliki besar yang sama dan arahnya sama. S dan A' (keduanya) terbukti salah.

\section{(Operasi Kesadaran Palsu)}

Hukum Faqya I dan II dapat menjawab pertanyaan mengapa Adam melakukan perbuatan Zhalim? Hukum Faqya I (Hukum Kesadaran Umum) point (1) "Semua makhluk hidup diatur dan dipelihara melalui suatu mekanisme tetap yang disebut Daya Hidup. Point (3) Daya hidup bekerja melalui mekanisme yang sama yaitu kesadaran." (4) "Setiap makluk hidup akan menggunakan kesadarannya atau tak menggunakan kesadarannya kecuali ada daya sadar lain yang bekerja untuk mengubahnya. Artinya Adam maupun Setan bekerja melalui mekanisme yang sama yaitu kesadaran. Semua makhluk hidup memiliki daya hidup dan semua manusia mengatur dan memelihara kehidupannya dengan kesadaran termasuk Adam dan Setan. Setan menggunakan operasi kesadaran palsu dalam membangun argumentasi. Apa yang membuat Adam berbuat zhalim karena menggunakan kesadaran palsu dari Setan. Atas dasar itulah keduanya dihukum sama-sama turun ke bumi karena keduanya sama-sama salah. Yang satu salah dalam menggunakan kesadaran dan yang satu mengikuti kesadaran yang salah.

Adam dalam hal ini terperdaya dalam mode kesadaran palsu dan ketaksadaran Setan. Adam yang semula menggunakan model kesadaran tak bersyarat berubah menjadi model kesadaran lain. Hukum membawa pada implikasi adanya Tiga jenis kesadaran.

Tiga Jenis Kesadaran
Berdasarkan hukum Faqya I dan II maka terdapat tiga jenis kesadaran yaitu (1) Sadar; (3) Taksadar; (4) Kesadaran Palsu. Keitga kesadaran inilah yang digunakan oleh semua makhluk hidup. Ketiga model ini selanjutnya dibagi menjadi dua yaitu model kesadaran ideal dan tak ideal. Pembagian ini dilandasi oleh fakta bahwa Adam dan isterinya telah menjalani kehidupan yang ideal di taman (jannah) lalu tiba-tiba jatuh ke Bumi hanya karena Adam menggunakan mode kesadaran palsu dan mode ketaksadaran. Hal ini membuktikan bahwa model sosial (kehidupan) yang ideal menggunakan model sadar sedangkan mode kesadaran palsu dan ketaksadaran membawa kepada kehidupan yang tidak ideal.

Dari kedua model kesadaran ini dapat terlihat jelas bahwa A hendak menjadikan A' sebagai personal yang ideal untuk mengelola kehidupan yang ideal. Akan tetapi M, J, dan S menolaknya karena ketiganya beralasan personal ideal dan kehidupan yang ideal itu tidak ada. Maka A memberikan daya sadar (DS) dalam bentuk pengetahuan, ekspresi, peraturan, dan petunjuk kepada $A^{\prime}$ untuk membuktikan personal ideal dan kehidupan sosial ideal itu ada, sebaliknya ada yang tak ideal melalui suatu mekanisme yang disebut uji kesadaran.

\section{Uji Kesadaran}

\section{Uji Pengetahuan Konseptual Personal Ideal.}

A memberikan daya sadar (DS) kepada A'. Daya sadar (DS) diberikan dalam bentuk pengetahuan konseptual sebesar F (Konsep benda Langit dan Bumi). Maka A' memberikan daya sadar sebesar F (Konsep benda Langit dan Bumi) juga. Untuk mengetahui A dan A' arahnya sama atau tidak maka A melakukan uji kesadaran melalui mekanisme pengujian dengan cara meminta A untuk menyebutkan Nama benda Langit dan Bumi. A' memberikan daya sadar (DS) dengan menyebutkan semua nama benda Langit dan Bumi. Arahnya sama, yaitu sama-sama menyebutkan dan besarnya juga sama. Hasil uji kesadaran adalah $\mathrm{F}$ sama dan arahnya juga sama, jadi A dan A' adalah benar.

Uji pengetahuan yang sama dilakukan pada $M$ dan hasilnya adalah salah. Uji 
pengetahuan juga dilakukan pada $\mathbf{J}$ dan hasilnya arahnya salah dan menolak. S tidak mengikuti uji pengetahuan.

Kesimpulan dari uji Pengetahuan Konseptual:

1) A' terbukti benar karena daya pikir dan daya ingatnya sama setelah melalui uji pengetahuan konseptual.

2) M terbukti salah karena daya pikir dan daya ingatnya tidak sama setelah melalui uji pengetahuan konseptual.

3) J terbukti salah karena daya pikir dan daya ingatnya tidak sesuai setelah melalui uji pengetahuan konseptual.

4) $S$ terbukti tidak mengikuti uji pengetahuan konseptual.

Implikasi dari kesimpulan uji Pengetahuan:

1. Jika terbukti A' adalah benar maka A' dan A adalah benar

2. Jika terbukti $A^{\prime}$ adalah benar maka M, J, dan $\mathrm{S}$ harus menerima A' sebagai personal ideal.

3. Jika terbukti A' adalah benar maka A mengetahui Rahasia Langit dan Bumi.

Implikasi ini membawa konsekuensi pada realitas sosial bahwa: 1) Personal ideal dipilih melalui uji kesadaran pengetahuan konseptual; 2) Personal ideal memiliki daya sadar dalam bentuk pengetahuan konseptual yang teruji benar ; 3) Kebenaran pengetahuan konseptual yang ideal adalah sesuainya antara daya pikir dan daya ingat; 4) Personal yang tidak teruji benar harus menerima Personal yang teruji benar. 4) kesadaran yang ideal adalah kesadaran yang bernilai benar.

Hukum kesadaran ini menyimpulkan: (1) bahwa kesadaran yang sama akan benarmembenarkan;; 2) kebenaran yang sama akan membentuk orbit kesadaran. Hukum ini disebut gravitasi kesadaran. (3) kesadaran yang menyimpang akan salah-menyalahkan. Hukum ini disebut aksi reaksi kesadaran

\section{Uji Ekspresional Personal Ideal.}

A memberikan daya sadar (DS) kepada A'. Daya sadar (DS) diberikan dalam bentuk perasaan sebesar $\mathrm{F}$ (perasaan yang dinyatakan disebut bahasa \& tak dinyatakan disebut emosi). Maka A' memberikan daya sadar sebesar F (bahasa \& emosi) juga. Untuk mengetahui A dan A' arahnya sama atau tidak maka A melakukan uji kesadaran melalui mekanisme pengujian dengan cara meminta A untuk mengekspresikan perasaan dengan bahasa dan emosi. A' memberikan daya sadar (DS) dengan menyebutkan semua nama bahasa perasaan danmengekspresikan emosi. Arahnya sama, yaitu sama-sama menyebutkan dan mengekspresikan dimana besarnya juga sama. Hasil uji kesadaran adalah besarnya $F$ sama dan arahnya juga sama, jadi A dan A' adalah benar.

Uji kesadaran yang sama dilakukan pada $M$ dan hasilnya adalah salah. Uji kesadaran juga dilakukan pada $\mathbf{J}$ dan hasilnya arahnya salah dan menolak. S tidak mengikuti uji kesadaran.

Kesimpulan dari uji ekspresi:

1) A' terbukti jujur (dinyatakan) karena bahasa dan emosinya sesuai setelah melalui uji ekspresi.

2) A' terbukti Tulus (emosi yang tak dinyatakan) karena bahasa dan emosinya sesuai setelah melalui uji ekspresi

3) M terbukti salah karena bahasa dan emosi tidak sesuai setelah melalui uji ekspresi.

4) J terbukti salah karena bahasa dan emosi tidak sesuai setelah melalui uji ekspresi.

5) $\mathrm{S}$ terbukti tidak mengikuti melalui uji ekspresi.

Implikasi dari kesimpulan uji ekspresi:

1. Jika teruji A' adalah jujur maka A' adalah berani

2. Jika teruji $A^{\prime}$ adalah mengekspresikan emosi (tak dinyatakan) sesuai maka $A^{\prime}$ adalah tulus.

3. Jika terbukti A' berani jujur maka M, J, dan $S$ harus menerima $A^{\prime}$ sebagai personal ideal melalui ekspresi.

4. M terbukti menyatakan ekspresi penerimaannya kepada A' sebagai personal dengan bersujud

5. J terbukti tidak menyatakan eskpresi penerimaannya kepada $A^{\prime}$ sebagai personal ideal dengan penolakan.

6. Jika terbukti J, tidak menyatakan ekspresi penerimaannya kepada A' maka J berdusta dan sombong.

7. Jika terbukti J berdusta dan sombong maka $\mathrm{J}$ dihukum dan diturunkan

8. Jika A' terbukti jujur dan tulus maka A mengetahui rahasia ekspresi yang dinyatakan dan yang tak dinyatakan. 
Implikasi ini membawa konsekuensi pada realitas sosial bahwa: 1) personal ideal dipilih melalui uji kesadaran ekspresional; 2) personal ideal memiliki daya sadar dalam bentuk ekspresional yang teruji jujur; 3) Kejujuran eskpresional yang ideal adalah sesuainya antara bahasa dan emosi; 4) personal yang tidak teruji jujur harus hormat pada personal ideal yang teruji jujur. 5) kesadaran yang ideal adalah kesadaran yang bernilai jujur.

Hukum kesadaran ini menghasilkan hukum: (1) bahwa kesadaran yang sama akan terima-menerima; 2) kejujuran yang sama akan membentuk orbit kesadaran. Hukum ini disebut Gravitasi kesadaran. (3) kesadaran yang menyimpang akan tolak menolak. Hukum ini disebut aksi reaksi kesadaran

\section{Uji Moral Kelompok Ideal}

A memberikan daya sadar (DS) kepada A' dan pasangan A'. Daya sadar (DS) diberikan dalam bentuk peraturan sebesar $\mathrm{F}$ (perintah \& larangan). Maka A' dan pasangan A' memberikan daya sadar sebesar -F (menjauhi perintah dan mendekati larangan). Untuk mengetahui $A^{\prime}$ beserta pasangan $A^{\prime}$ arahnya sama atau tidak dengan $\mathrm{A}$, maka $\mathrm{A}$ melakukan uji moral melalui mekanisme pengujian dengan cara meminta $A^{\prime}$ dan pasangannya untuk tidak mendekati S. A' dan pasanganya memberikan daya sadar (DS) dengan mendekati $S$ dan menikmati $S$. Arahnya tidak sama dengan A, Hasil uji moral adalah besarnya $\mathrm{F}$ tidak sama dan arahnya terbalik, jadi A' dan pasangannya adalah salah.

Uji moral yang sama tidak dilakukan pada M dan J. Uji moral juga dilakukan pada S dan hasilnya $S$ berdusta dan menipu.

Kesimpulan dari uji moral:

1) A' dan pasanganya terbukti zhalim karena perintah dan larangan tidak sesuai setelah melalui uji moral.

2) S terbukti zhalim karena berdusta dan menipu.

Implikasi dari uji moral:

1) Jika terbukti $A^{\prime}$ dan pasangannya zhalim maka A' dan pasangannya diturunkan

2) Jika teruji $S$ berdusta dan menipu maka $S$ di hukum dan diturunkan .

3) Jika terbukti $A^{\prime}$ dan pasangannya serta $S$ salah maka keduanya di hukum dan turun.
Implikasi ini membawa konsekuensi pada realitas sosial bahwa: 1) kelompok ideal dipilih melalui uji kesadaran moral ; 2) kelompok ideal memiliki daya sadar dalam bentuk moral yang teruji pada perintah dan larangan; 3) moral kelompok yang ideal adalah sesuainya antara perintah dan larangan; 4) kelompok yang tidak teruji bermoral harus dihukum dan diturunkan. 4) kesadaran yang ideal adalah kesadaran yang bernilai Adil.

Hukum kesadaran ini menghasilkan hukum: (1) bahwa kesadaran yang sama akan dekat-mendekat; 3) kesadaran yang sama akan membentuk kelompok kedekatan. (2) Hukum ini disebut Gravitasi kelompok. (3) bahwa kesadaran yang berbeda akan jauh-menjauh; 3) kesadaran yang berbeda akan membentuk kelompok terpecah-pecah. (2) Hukum ini disebut aksi reaksi kelompok

\section{Uji Karakter Kelompok Ideal.}

A memberikan daya sadar (DS) kepada A' dan pasangan A'. Daya sadar (DS) diberikan dalam bentuk hukuman sebesar $F$ (takut dan sedih). Maka A' dan pasangan A' memberikan daya sadar sebesar F (Menyesal dan taubat). Untuk mengetahui $A^{\prime}$ beserta pasangan A' arahnya sama atau tidak dengan A, maka A melakukan uji karakter melalui mekanisme pengujian dengan cara meminta A' dan pasangannya mengucapkan kalimat taubat. A' dan pasanganya memberikan daya sadar (DS) dengan mengucapkan kalimat taubat. Arahnya sama dengan A, Hasil uji karakter adalah besarnya $\mathrm{F}$ sama dan arahnya sama, jadi A' dan pasangannya adalah benar.

Uji Karakter yang sama tidak dilakukan pada M, J, dan S.

Kesimpulan dari uji Karakter:

A' dan pasanganya terbukti benar karena ucapan dan perbuatannya sesuai setelah melalui uji karakter.

Implikasi dari kesimpulan uji karakter:

1) Jika teruji A' dan pasangannya benar maka A' dan pasangannya diampuni.

2) Jika teruji $A^{\prime}$ dan pasangannya mendapat ampunan maka $A^{\prime}$ dan pasangannya kembali menjadi kelompok ideal

3) Jika A'. dan pasangannya diampuni dan menjadi kelompok ideal kembali maka A berkarakter penerima tobat. 
Implikasi ini membawa konsekuensi pada realitas sosial bahwa: 1) kelompok ideal dipilih melalui uji karakter; 2) kelompok ideal memiliki daya sadar dalam bentuk karakter yang teruji pada ucapan dan perbuatan; 3) karakter kelompok yang ideal adalah sesuainya antara ucapan dan perbuatan; 4) kelompok yang tidak teruji berkarakter harus tetap dihukum. 4) kesadaran kelompok yang ideal adalah kesadaran yang bernilai reflektif (penyesalan dan pertaubatan).

Hukum kesadaran ini menghasilkan hukum: (1) bahwa kesadaran yang sama akan maaf-memaafkan; 2) kesadaran yang sama akan membentuk orbit karakter. Hukum ini disebut Gravitasi Kesadaran kelompok; (3) kesadaran yang menyimpang akan dendammendendam. Hukum ini disebut aksi-reaksi kesadaran kelompok

\section{Uji Persepsional Masyarakat Ideal}

A memberikan daya sadar (DS) kepada A' dan pasangannya, Daya sadar (DS) diberikan dalam bentuk persepsional sebesar F (Mengikuti Petunjuk). Maka jika A' dan pasangannya, memberikan daya sadar sebesar F (Mengikuti Petunjuk) juga. Maka untuk mengetahui A dan $A^{\prime}$ dan pasangannya arahnya sama atau tidak maka A melakukan uji Persepsional melalui mekanisme pengujian dengan cara meminta $A^{\prime}$ dan pasangannya untuk mendengar dan melihat pertunjuk yang datang. jika A' dan pasangannya, memberikan daya sadar sebesar F (Mengikuti Petunjuk) arahnya sama, besarnya juga sama. Maka Hasil uji persepsi adalah A' dan pasangannya adalah benar.

Uji Persepsi yang sama dilakukan pada J, dan S.

Kesimpulan dari uji persepsional:

1. Jika A' dan pasangannya terbukti benar daya dengar dan daya lihatnya sama setelah melalui uji persepsi maka A' dan pasangannya benar mengikuti petunjuk

2. Jika $\mathbf{J}$ terbukti benar daya dengar dan daya lihatnya sama setelah melalui uji persepsi maka $\mathrm{J}$ benar mengikuti petunjuk

3. Jika A' dan pasangannya terbukti benar daya dengar dan daya lihatnya sama setelah melalui uji persepsi maka A' dan pasangannya benar mengikuti petunjuk
4. Jika S terbukti benar daya dengar dan daya lihatnya sama setelah melalui uji persepsi maka $\mathrm{S}$ benar mengikuti petunjuk

Implikasi dari kesimpulan uji Pengetahuan:

1. Jika terbukti A' dan pasangannya adalah benar maka $A^{\prime}$ dan pasangannya tidak bersedih dan tidak takut

2. Jika terbukti $\mathbf{J}$ adalah benar maka $\mathbf{J}$ tidak bersedih dan tidak takut

3. Jika terbukti $\mathrm{S}$ adalah benar maka $\mathrm{S}$ tidak bersedih dan tidak takut

Implikasi ini membawa konsekuensi pada realitas sosial bahwa: 1) masyarakat ideal dipilih melalui uji persepsional; 2) masyarakat ideal masyarakat memiliki daya sadar dalam bentuk persepsi yang teruji pada penglihatan dan pendengaran; 3) Persepsional masyarakat ideal adalah sesuainya antara penglihatan dan pendengaran; 4) masyarakat yang tidak mengikuti petunjuk teruji sombong dan khawatir harus dilawan, dihukum, dan diturunkan. 4) kesadaran masyarakat yang ideal adalah kesadaran yang bernilai bahagia dan tenang.

Hukum kesadaran ini menghasilkan hukum: (1) bahwa kesadaran sosial yang sama akan ikut-mengikuti; (2) kesadaran sosial yang ideal akan membentuk masyarakat ideal. Hukum ini disebut Gravitasi sosial; (3) kesadaran yang menyimpang akan jauhmenjauh. Hukum ini disebut aksi-reaksi kesadaran sosial

Berdasarkan uji kesadaran tersebut maka dapat ditemukan ciri sistem sosial yang ideal yaitu:

1. Ciri personal yang ideal secara intelektual adalah: 1) Personal ideal ditentukan melalui uji kesadaran pengetahuan; 2) Personal ideal memiliki daya sadar dalam bentuk pengetahuan konseptual yang teruji benar; 3) Kebenaran pengetahuan konseptual yang ideal adalah sesuainya antara daya pikir dan daya ingat; 4) Personal yang tidak teruji benar harus menerima Personal yang teruji benar. 5) kesadaran personal yang ideal adalah kesadaran yang bernilai benar.

2. Ciri personal yang ideal secara ekspresional adalah; 1) personal ideal ditentukan melalui uji kesadaran ekspresional; 2) personal ideal memiliki 
daya sadar dalam bentuk ekspresi yang teruji jujur; 3) Kejujuran eskpresional adalah sesuainya antara bahasa dan emosi; 4) personal yang tidak teruji jujur harus bersujud pada ideal yang teruji jujur.

4) kesadaran personal yang ideal adalah kesadaran yang bernilai jujur.

3. Ciri kelompok yang ideal secara moral adalah; 1) kelompok ideal ditentukan melalui uji kesadaran moral; 2) kelompok ideal memiliki daya sadar dalam bentuk moral yang teruji pada perintah dan larangan; 3) moral kelompok yang ideal adalah sesuainya antara perintah dan larangan; 4) kelompok yang tidak teruji bermoral harus dihukum dan diturunkan.

4) kesadaran kelompok yang ideal adalah kesadaran yang bernilai Adil.

4. Ciri kelompok yang ideal: 1) kelompok ideal ditentukan melalui uji karakter; 2) kelompok ideal memiliki daya sadar dalam bentuk karakter yang teruji pada ucapan dan perbuatan ; 3) karakter kelompok ideal kelompok adalah sesuainya antara ucapan dan perbuatan; 4) kelompok yang tidak teruji berkarakter harus tetap dihukum. 5) kesadaran kelompok yang ideal adalah kesadaran yang bernilai reflektif (penyesalan dan pertaubatan).

5. Ciri masyarakat yang ideal 1) masyarakat ideal ditentukan melalui uji persepsional;

2) masyarakat ideal masyarakat memiliki daya sadar dalam bentuk persepsi yang teruji pada penglihatan dan pendengaran;

3) Persepsional masyarakat ideal adalah sesuainya antara penglihatan dan pendengaran; 4) masyarakat yang tidak mengikuti petunjuk teruji sombong dan khawatir harus dilawan, dihukum, dan diturunkan. 4) kesadaran masyarakat yang ideal adalah kesadaran yang bernilai bahagia dan tenang

Dengan demikian untuk mengetahui personal ideal dapat diukur dengan dua faktor yaitu 1) Faktor pengetahuan (intelektual); 2) Faktor ekspresional; untuk mengetahui kelompok yang ideal dapat diukur dengan dua faktor yaitu: 1) Faktor peraturan; 2) Faktor Karakter; sedangkan untuk mengetahui masyarakat yang ideal dapat diukur dengan satu faktor yaitu Faktor Petunjuk.
Hal yang sama untuk mengetahui personal takideal dapat diukur dengan dua faktor yaitu 1) Faktor pengetahuan (intelektual); 2) Faktor ekspresional; untuk mengetahui kelompok yang takideal dapat diukur dengan dua faktor yaitu: 1) Faktor peraturan (moral); 2) Faktor Karakter; sedangkan untuk mengetahui masyarakat yang takideal dapat diukur dengan satu faktor yaitu Faktor Petunjuk.

Dengan demikian realitas sosial atau sistem sosial diatur dan dipelihara oleh hukumhukum kesadaran. Hukum kesadaran bekerja dalam dua bentuk yaitu hukum gravitasi kesadaran dan hukum aksi reaksi kesadaran. Hukum gravitasi kesadaran bekerja pada tiga level yaitu level personal, kelompok, dan masyarakat. Hukum aksi reaksi kesadaran juga bekerja pada tiga level yaitu personal, kelompok, dan masyarakat.

Dengan demikian langkah pertama dari ilmu sosial membangun teori telah terjawab bahwa hukum yang berlaku pada kehidupan sosial (sistem sosial) adalah hukum kesadaran. Langkah selanjutnya adalah membaca realitas empiris. Bagaimana ilmu alam melihat realitas empiris? Ilmu alam melihat realitas empiris melalui dua cara yaitu realitas normal dan realitas deviant (menyimpang). Realitas normal adalah realitas yang sesuai dengan model ideal. Kita sudah menemukan model ideal dalam ilmu sosial yaitu kesadaran ideal. Kesadaran yang ideal bekerja pada tiga level yaitu personal, kelomok dan masyarakat

Model ini selanjutnya menjadi cara melihat realitas sosial. Mana realitas sosial yang ideal dan realitas sosial yang menyimpang. Realitas sosial yang ideal terbangun dari kesadaran. Sedangkan realitas yang menyimpang dibangun dari kesadaran palsu dan ketaksadaran. Realitas yang dibentuk oleh kesadaran palsu dan ketaksadaran inilah yang perlu mendapatkan penjelasan ilmiah. Maka ilmuan sosial perlu membuat hipotesis (langkah ketiga). Langkah selanjutnya adalah melakukan riset ilmiah. Hasil riset akan melahirkan teori sosial yang handal dan berkelanjutan (langkah keempat).

Dengan demikian kita sudah menyelesaikan pola kerja Ilmu Alam ke dalam Ilmu sosial. Pola kerja ini menghasilkan 
framework Riset ilmu sosial di masa depan. Kita perlu menguji kehandalan kerangka kerja ini dan untuk membutkikan bahwa pola kerja ilmu sosial sama handalnya dengan pola kerja ilmu alam. Kerangka kerja tersebut dapat dsusun sebagai berikut:

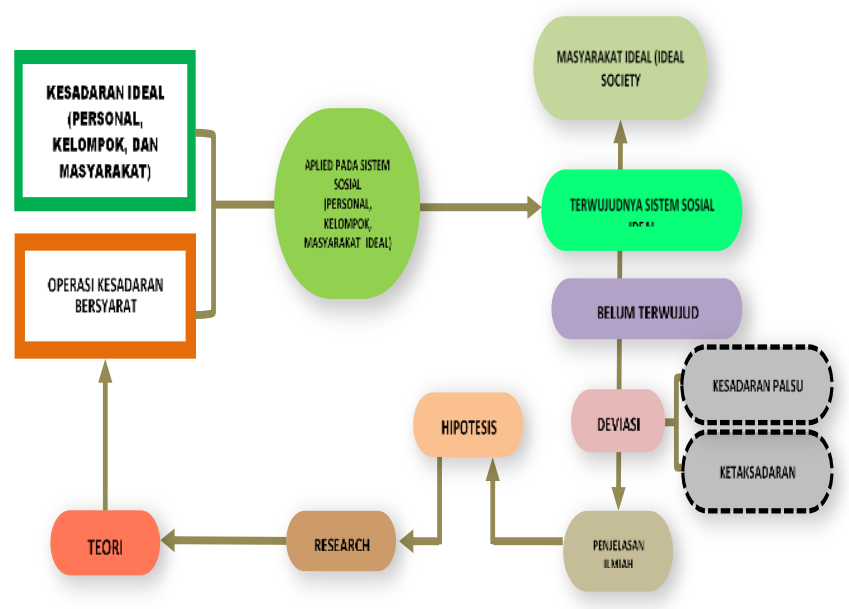

Gambar: Framework Riset Ilmu Sosial di Masa Depan

1. Dalam realitas sosial kita akan menemukan empat jenis kesadaran yang beredar seharihari. Keempat kesadaran ini akan menjadi landasan dalam membentuk sistem sosial kita sekarang dan yang akan datang.

2. Namun kita mempunyai agenda untuk membangun masyarakat ideal maka tidak semua kesadaran cocok untuk digunakan, maka untuk kepentingan membangun masyarakat ideal kita hanya menggunakan kesadaran ideal saja.

3. Pertanyaannya apakah masyarakat ideal itu sudah tercapai, jika jawabanya belum tercapai berarti selama ini realitas sosial yang kita bangun telah mengalami penyimpangan.

4. Penyimpangan terjadi karena kesadaran yang menjadi landasan bangunannya adalah kesadaran palsu dan ketaksadaran.

5. Penyimpangan realitas sosial ini perlu mendapatkan penjelasan ilmiah

6. Untuk mendapatkan penjelasan ilmiah dibutuhkan teori, hipotesis, hukum, terlebih dahulu.

7. Hipotesis ini akan menjadi proposal riset

8. Hasil riset akan melahirkan teori

9. Semua teori diterima sebagai operasi kesadaran jika telah terbukti benar.
10. Semua teori yang terbukti benar akan menjadi pendukung operasi kesadaran.

\section{Kesimpulan}

Berdasarkan kajian tersebut di atas

maka dapat disimpulkan bahwa:

1. Lima langkah ilmu sosial agar sehebat dan sehandal ilmu alam yaitu: 1) membuat model sosial ideal; 2) memlihat realitas sosial saat ini; 3) Membuat huku, dan hipotesis atas realitas sosial yang menyimpang dari model ideal; 4) Menyusun teori sosial; 5) Menerapkan teori sosial pada realitas sosial.

2. Hukum yang berlaku pada dunia hidup (dunia sosial adalah hukum kesadaran)

3. Hukum kesadaran ada dua yakni hukum kesadaran umum dan hukum kesadaran khusus

\section{DAFTAR PUSTAKA}

Alquran (2019) Alquran Cordova. Syamil: Jakarta

Baars, B. J. (1988). A cognitive theory of consciousness. Cambridge Cambridgeshire ; New York: Cambridge University Press.

Baars, B. J., \& Laureys, S. (2005). One, not two, neural correlates of consciousness. Trends Cogn Sci, 9(6), 269; author reply 270. doi:10.1016/j.tics.2005.04.008 Barttfeld, P., Uhrig, L., Sitt, J. D., Sigman, M., Jarraya, B., \& Dehaene, S. (2015).

Baars, B.J. (1988), A Cognitive Theory of Consciousness (New York: Cambridge University Press)

Brentano, F. (1982). Psikolog Deskriptive. Hamburg:

Meiner. Publikasi 1

Carruthers, P. (2000). Phenomenal consciousness : a naturalistic theory. Cambridge, UK ; New York: Cambridge University Press

Chalmers, D. (1996). The conscious mind : in search of a fundamental theory. New York: Oxford University Press

Crick, F. (1994), The Astonishing Hypothesis: The scientific search for the soul, (London: Simon \& Schuster)

Dennett, DC (1991), Consciousness Explained, (London: Allen Lane, The Penguin Press) 
Farisco, M. 2019. Brain, consciousness and disorders of consciousness at the intersection of neuroscience and philosophy. Digital Comprehensive Summaries of Uppsala Dissertations from the Faculty of Medicine 1597. 63 pp. Uppsala: Acta Universitatis Upsaliensis. ISBN 978-91-513-0749-7.

Gazzaniga, M. (2011). Who's In Charge? Free Will and the Science of the Brain. New York: Harper Collins.

Gennaro, R. J. (2012). The consciousness paradox : consciousness, concepts, and higher-order thoughts. Cambridge, Mass.: MIT Press

Hameroff, S., \& Penrose, R. (2014). Consciousness in the universe: a review of the 'Orch OR' theory. Phys Life Rev, 11(1), 39-78. doi:10.1016/j.plrev.2013.08.002

Koch, C. (2012). Consciousness: Confessions of a Romantic Reductionist. Cambridge, MA: MIT Press

Kriegel, U. (Forthcoming). What is the philosophy of consciousness? In U. Kriegel (Ed.), Oxford Handbook of the Philosophy of Consciousness. Oxford: Oxford University Press.

Kriegel, U., \& Williford, K. (2006). Selfrepresentational approaches to consciousness. Cambridge, Mass. ; London: MIT

Metzinger, T. (2000a). Neural Correlates of Consciousness: Empirical and Conceptual Questions. Cambridge, MA: MIT Press.

Metzinger, T. (Ed.) (2000b). Neural Correlates of Consciousness: Empirical and Conceptual Issues. Cambridge, MA: MIT Press

Muadz, H (2016). Anatomi Sistem Sosial: Rekonstruksi Sistem Sosial dengan Pendekatan Nalar Sistem. Gelar Hidup Press: Mataram

Sen, S. (2008), 'The Vedic-Upanisadic concept of Brahman (the highest God)', in A. Eshleman

Sloman, A. (1991), 'Developing concepts of consciousness', Behavioral and Brain Sciences, hlm.694-695.
Sperry, R.W. (1969), 'A modified concept of consciousness', Psychological Review,

Sperry, R.W. (1969), 'A modified concept of consciousness', Psychological Review, 76(6), pp.

Tye, M. (1995). Ten problems of consciousness : a representational theory of the phenomenal mind. Cambridge, Mass.: MIT Press

Velmans, M. (2009), Understanding Consciousness, Edition 2, (London: Routledge/ 